\title{
Significance of Leaf Surface of Urban Trees to Monitor Airborne Particle Pollutants Nearby Superphosphate Fertilizer Plant
}

\author{
El-Khatib, A. A ${ }^{1 *}$, El-Shanawany, A. A. ${ }^{2}$, El-Amery, E. M $^{2}$ \\ Botany Department, Sohag University, Faculty of Science ${ }^{1}$, Egypt. \\ Botany Department, Al-Azhar University-Assiut, Faculty of Science ${ }^{2}$, Egypt..
}

Rec. 17 Aug, 2010 Accpt. 10 Dec 2010

\begin{abstract}
Three common tree species in the areas nearby Assiut Superphosphate Fertilizer Plant were selected to monitor the airborne particle pollutants along the physical year 2009-2010. The relative percentage value of the leaf deposit particles depends on the interaction between seasons, sites and tree species, where highly significant effects $(P<0.001)$ were recorded in between. Morphological analysis by SEM of the leaf deposit confirms the presence of different particle species of PM2.5, PM10 and PM50. Quantitatively, PM2.5 dominated other particle types, reflecting the importance of the anthropogenic source, like Superphosphate Fertilizers Plant emission, in the air pollution status prevailing in the study area. The chemical analysis of the leaf particulate deposits exhibited a significant correlation with chemic indicator species to the fertilizers manufacture, where the particulate mass of the leaf deposit samples showed correlation with foliar $\mathrm{Fe}(\mathrm{r}=0.542), \mathrm{Cd}(\mathrm{r}=0.528), \mathrm{Ca}(0.805)$ and PO4 $(\mathrm{r}=0.605)$, reflecting the possibility of using tree species as bio-monitors for the air particulate matter pollution.
\end{abstract}

Key words: Airborne particle; pollutants; superphosphate fertilizer; urban trees.

\section{Introduction}

Progressive industrialization and the shift of polluting industrial activities from the industrialized countries to the so-called Third World together with insufficient emission control due to the lack of economic resources and of environmental awareness have caused serious environmental problems in developing and threshold countries. Superphosphate fertilizer Plants are considered ones of the stationary sources for production of fugitive particles onto the atmosphere, where single or normal, phosphate is produced, with varied phosphorus content of phosphorous pentoxide (P2O5) according to the type of acid use to pulverize phosphate rock (EPA U.S., 1979). According to (UNEP, 1998). atmospheric pollutants emitted by the fertilizer industry can include gaseous ammonia (NH3) and ammonium salt aerosols, nitric and nitrous oxides (NOx and $\mathrm{N} 2 \mathrm{O}$ ), fluorine (as $\mathrm{SiF} 4$ and $\mathrm{HF}$ ), oxides of sulphur (SOx), fertilizer dust, acid mists, and radiation (from phosphogypsum). In addition, the phosphate fertilizer industry is contributed to air heavy metal pollution, especially for cadmium metal. The acidulation of phosphate rock partitions the cadmium between the fertilizer product and the by-products, mainly the phosphorgypsum arising from phosphoric acid production (UNEP, 1998). However, the phosphate fertilizer industry shares the responsibility for the production of the secondary pollutants.

The monitoring processes of these atmospheric pollutants are very expensive and time consumed, if proceed with the traditional manner (instrumentally). Nowadays, biomonitoring is more recommended, especially it is proceed in cheap,

\footnotetext{
* Corresponding author:

Dr. El-Khatib, A.A
}

$\checkmark$ aaelkhatib@yahoo.com 
quickly, and accurate manner, where biological responses can be considered more representative than data supplied by chemical or physical detectors, in that they are spatially and temporally extensive; moreover, they allow for estimating both the levels of pollutants and, even more important, the impact on biological receptors (Gian et al., 2007).

In urban area, many studies (Pyatt, 2001; Avila et al., 2003; Free-Smith et al., 2004; Sardans and Penuelas, 2005; El-Khatib, et al., 2007). underline the use of tree leaves for pollution bio-monitoring. Depending on the structural properties of leaf surface, tree can act as biological absorbers or filters of pollutants (Wittig, 1993; Becket et al., 1998; El-Khatib and El-Swaf, 2001). In this way, they remove huge quantities of gaseous pollutants and airborne particles, thus improving the quality of the environment. The use of plant surfaces to reduce particle concentration was discussed by (Lohr and Pearson, 1996; and El-Khatib et al., 2004). The present study was designed to study the efficiency of leaf surface of urban trees as a tool to monitor the emission imposed by Assuit Superphosphate Fertilizers Plant.

\section{Materials and Methods The study area}

Mnaqabad is a small village locates north of Assiut City, Egypt and host the Superphosphate Fertilizer Plant. For purpose of this study, three sites in the areas nearby the Superphosphate Fertilizer Plant (latitude $27^{\circ}$ $12^{\prime} 1,80^{\prime \prime} \mathrm{N}$ and longitude $31^{\circ} 6{ }^{\prime} 51,84^{\prime \prime} \mathrm{E}$ ) were selected as: site (1): N-E of the plant; site (2) $\mathrm{N}-\mathrm{W}$ of the plant; and site (3) S-E of the plant to cover the different directions of the plant emission load. Sites away from the impact of the pollution emission of the plant were selected as control. According to (Egyptian Environmental Affairs Agency, 2006). the climatic characteristic of the study area reveals that air temperature is ranging from $15.3^{\circ} \mathrm{C}$ to $30.3^{\circ} \mathrm{C}$; the annual mean of wind velocity is 7.5 knots/hour, with maximum peak during spring (8.3 knots/hour) in the N-W direction, and. the annual mean of relative humidity is $38 \%$ and the annual mean of rain fall $0.7 \mathrm{~mm}$.

\section{Sampling}

Common tree species growing at the studied sites, belonging to different families, were selected for the study purpose. The identification of tree species was according to (Boulus, 2000). These tree species are Eucalyptus globules (Myrtaceae ); Ficus nitida (Moraceae) and Zizyphus spina-christia (Ramnaceae). Leaf samples were collected along the period from May 2009 to May 2010. The detached leaves were kept in plastic bags, placed in ice-box, and transported to the laboratory for further investigation.

\section{Deposit particulate mass}

The mass of particulate deposited on the leaf surface of the studied tree species was determined gravimetrically according to the methods of (Lau and Lak, 2001; and Prusty et al., 2005). It expressed in $\mathrm{g} / \mathrm{m}^{2}$. The relative percentage value was computed based on the value of the corresponding control.

\section{Deposit particulate speciation}

Scanning electron microscopy (SEM) was used to investigate the morphological properties of the collected particles. The specimens were fixed on specific holder using a specific double Sticker (Carbon sticker), (Tomašević et al., 2005), and then the samples were coated with gold palladium under vacuum using Sputterer (sputter coater JFC1100E). Coated specimens were examined for the different particle species (PM2.5, PM10, and PM50) and counted the density for each species in a measured leaf surface of $100 \mu \mathrm{m}^{2}$ from the different samples. They were photographed by SEM (JSM-5300LV; JEOL) at magnifications from $500 \mathrm{X}$ while the electron beam energy was fixed at $30 \mathrm{KeV}$

\section{Chemistry of leaf Particulate deposit}

Chemical analyses for the leaf deposit were carried out to determine chemical indicator species of superphosphate fertilizer as: heavy metals, $\mathrm{Cd}$ and Fe (klarschlammverodung et al., 1982). 
calcium (Schwarzenbach and Biedermann, 1948). and phosphorus (Andrew et al., 1995).

\section{5-Statistical Analysis}

The variations and correlation between means were calculated using Minitab statistical package. MANOVA analysis was used to calculate the significant differences among means and also the interaction between the studied factors at levels; 0.05, 0.01 and 0.001 . while Pearson correlation matrix was used to computed the correlation coefficient between the studied parameters.

\section{Results \& Discussion}

The present study reflects the role played by the superphosphate fertilizer plant as a source of particulate matter air pollutants. The quantification of the deposit mass on the leaf surface of the studied plant species growing at the different study sites around the plant was carried out (Figure 1). All tree species exhibited in between significant variations $(P<0.001)$ in their particulate deposit mass, and also, in comparison with those of the corresponding control sites. In this concern, (Nowak, 1994) reported that particulate matter (PM) interception capacity of trees may be depend on their surface geometry, phyllotaxy, leaf external characteristics (such as rough, wrinkle, hairs, cuticle, oil, etc.), and plant height and canopy of trees. Moreover, the climatic factors prevail in the study area, especially wind velocity and direction appeared to be having influence on the value of the particulate deposit mass, where F. nitida growing at the site (3) showed the highest mean value $(1503.4 \%)$ and $Z$. spina-christi growing at site (2) showed the lowest mean value $(480.2 \%)$. It is important to mention that the wind direction in the study area is from the North West direction, which demonstrates the ability of wind to carry particulate pollutants when it crosses the plant to the south-east direction, where there is site (3). Also, the leaf samples of $F$. nitida dominated other samples in their content of particulate deposit (3057.1\%) during spring season, where the wind velocity attained its maximum value ( $8.3 \mathrm{knots} / \mathrm{hour})$. This is clarifying the importance of the interaction between sites, seasons, and tree species on the relative percentage of leaf particulate deposits, especially when the variance analysis results were considered that confirm the highly significant effect $(P<0.001)$.

Speciation of the leaf particulate deposits by scanning electron microscopy confirms the presence of high amount of PM2.5 and PM10 particle species in comparison to PM50 (Figure 2). The distribution of PM particles differed between abaxial and adaxil leaf surface (Plate 1-3) showing higher density on the adaxil one. Leaf samples of $F$. nitida growing at site (3) exhibited the highest value of PM 2.5 (90.91\%). according to the finding of (Vallius, 2005). this is considered as indicators for the anthropogenic source of air pollution that contains particles of small diameter, especially heavy metals like $\mathrm{Cd}$, and reflecting the main contribution of Superphosphate Plant emission in the prevailing air pollution status at the study area. Also, samples of $Z$. spina-christi exhibited higher values of PM50 than the other samples reflecting the role of natural source in the leaf deposit, like phosphorus particles. This is driven from and improves by the results of chemical analyses carried out to the leaf deposits of the studied tree species during the present investigation. Our results revealed that the relative percentage value of $\mathrm{Cd}$ exhibited highly significant variations $(P<0.001)$ between sites (Figure 3), exhibiting its maximum value in the leaf deposit of $F$. nitida growing at sites (3) (being, 400.1\%). Spring season dominated other seasons in the leaf deposit content of $\mathrm{Cd}$ with value of $837.9 \%$. In this concern, (Lugon-Moulian et al., 2006) reported that phosphate fertilizers production can contain high Cd levels due to the presence of cadmium in the phosphate rock used for their manufacture. It is well known that industries that employ thermal processes, e.g., iron production, fossil fuel combustion, fertilizers, and cement manufacture; all release airborne cadmium (ex. Fabiano et al., 2006). From the ecological point of view, the spatial 
distribution of trace elements identifies areas receiving higher industrial emission by their elevated $\mathrm{Cd}$ contents and regions affected preferentially by traffic-derived emission based on elevated $\mathrm{Zn}, \mathrm{Pb}$ and $\mathrm{Fe}$ contents. Therefore, foliar trace element analysis may preferentially serve as a complementary method to enviromagnetics in areas where industrial emission is suspected or has to be evaluated (Lehndorff and Schwark, 2010).

The recorded data of leaf deposit Fe (Figure 4) exhibited maximum value $(309 \%)$ in the leaf deposit samples of $Z$. spina-christi growing at site (2) during the summer season, while the minimum value $(183 \%)$ was in the samples of $F$. nitida growing at site (3) during the winter season. To rationalize these results, it is important to mention that, site (2) was in area closed to the Assiut-Cairo railways road and affected by the vehicle emission more than the other study sites.

(Figure 5) shows the relative percentage of the phosphorus in the tree leaf deposits collected from the different sites during the study period. It is obvious that, variations in the relative percentage values of phosphorus were pronounced and very highly significant $(P<0.001)$ among sites. The maximum relative percentage value of the phosphorus was recorded in the leaf samples of $F$. nitida growing at site (3), being as $131.1 \%$, while the minimum relative percentage value $(113.2 \%)$ was recorded in the leaf samples of E. globulus growing at site (1). In comparison, all species exhibited significant difference $(P<0.001)$ from those of corresponding control. It obvious that the relative percentage of the deposit phosphorus affected by the interaction between site, species and season, where there was a highly significant difference $(P<0.001)$ in between.

Regarding Ca leaf deposit content, the plant species exhibited in between variations in their total foliar content during the study period (Figure 6). Based on the mean potential load value of the studied plant species, sites were arranged in the order as: site (3)> site (1)> site (2). Control sites appeared to be host the species of minimum mean values of deposit $\mathrm{Ca}$, in comparison with those of corresponding species growing at the polluted sites. The results of the two ways analysis of variance exhibited highly significant differences $(p<0.001)$ between sites, and between them and their corresponding control sites. Generally, maximum mean of relative percentage value of $\mathrm{Ca}$ was recorded in the leaf samples of $F$. nitida growing at site (3), being as $403.1 \%$, while the minimum value (192.1\%) was in the leaf samples of, Z. spinachristi growing at site (2). It appears from the recorded data that the relative percentage of the deposit Ca significantly affected $(P<0.001)$ by the interaction between sites, seasons and tree species.

In conclusion, Owing to the present study, leaf Deposits particulate mass appeared to be depend on the pollutants site load and the tree species itself. Season appears to be having impact on the air particulate matter removal. Spring exhibited rich season for the deposit particulate capturing by the different studied species growing at the different study sites. This may be attributing to the fact that the superphosphate fertilizer plant increases its production during this period; an increase in the amount of air pollutants resulting from manufacturing operations, which emitted to the surrounding air and then fall as tree leaf deposits. The Leaf particulate deposits exhibited a significant positive correlation with foliar $\mathrm{Fe}(\mathrm{r}=0.542), \mathrm{Cd}(\mathrm{r}=$ $0.528), \mathrm{Ca}(0.805)$ and PO4 ( $\mathrm{r}=0.605)$, of the different studied species growing at the studied sites during the study period, reflecting the possibility of using tree species as biomonitors for the air particulate matter air pollution. Based on the present results $F$. nitida appeared to be the most suitable tree species for bio-monitoring air quality improvement, than other studied species, especially in the area of the superphosphate plant. This is in agreement with the findings of many studies (Free-smith et al., 2004, ElKhatib et al., 2007; 2008). which recommended the using of Ficus nitida tree species for bio-monitoring of air pollution in the urban environment. 

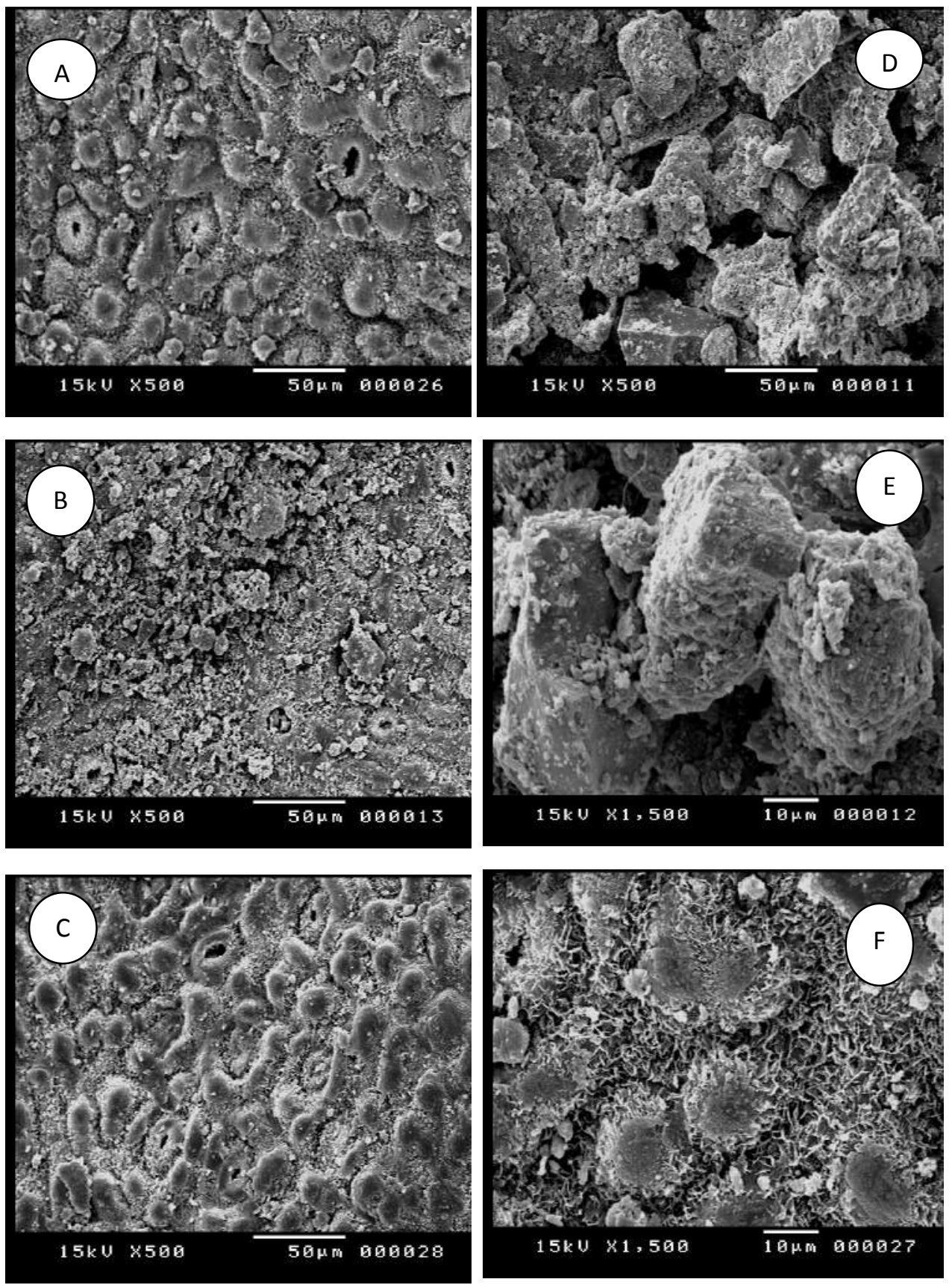

Plate (1): Scanning electron micrographs of leaf surface of E. globulos growing at the control (adaxial $(\mathrm{A}, \mathrm{B})$, abaxial $(\mathrm{C})$ ) and polluted sites (adaxial (D, E), abaxial (F)). 

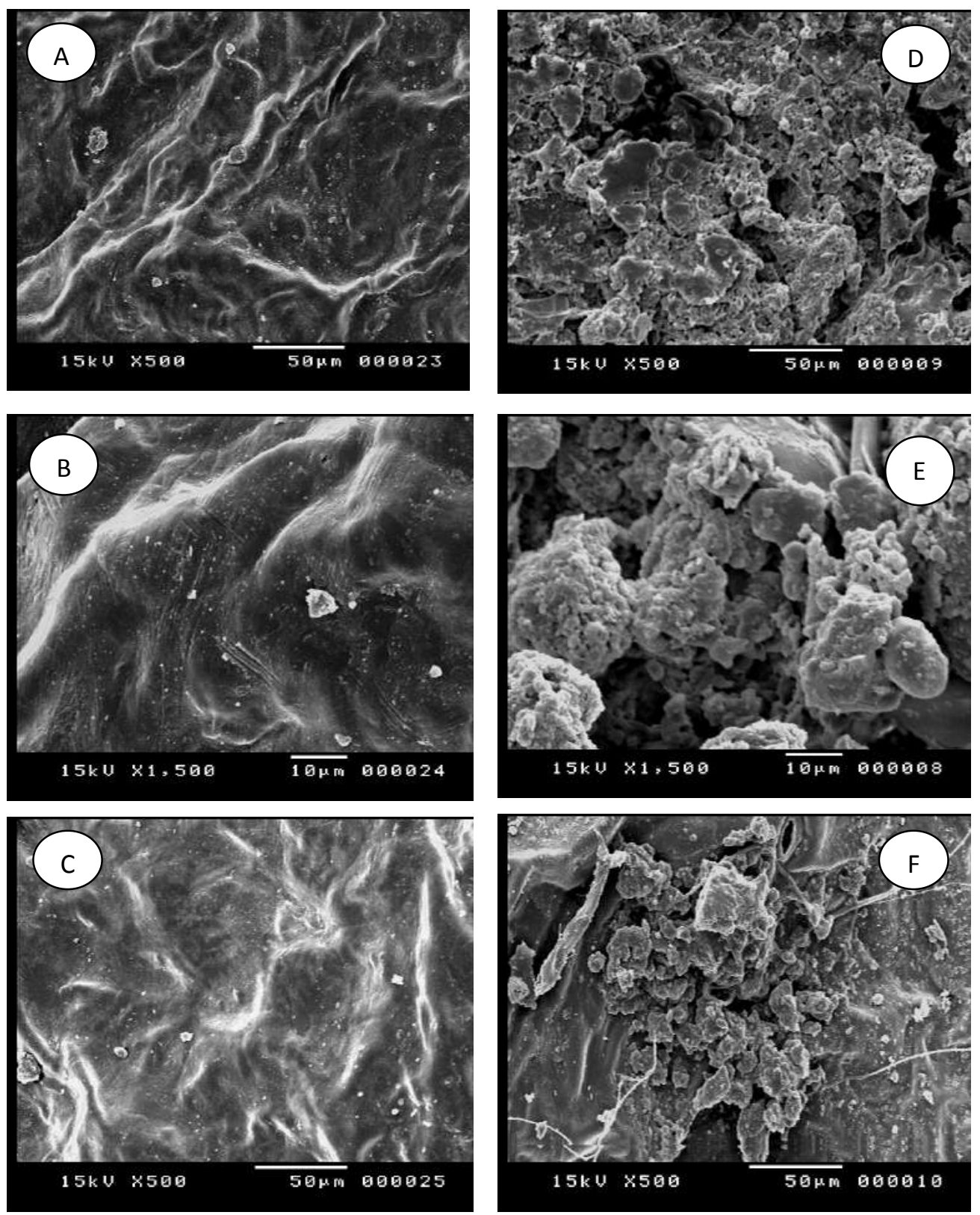

Plate (2): Scanning electron micrographs of leaf surface of $Z$. spina-christi growing at the control (adaxial $(\mathrm{A}, \mathrm{B})$, abaxial (C)) and polluted sites (adaxial (D, E), abaxial (F)). 

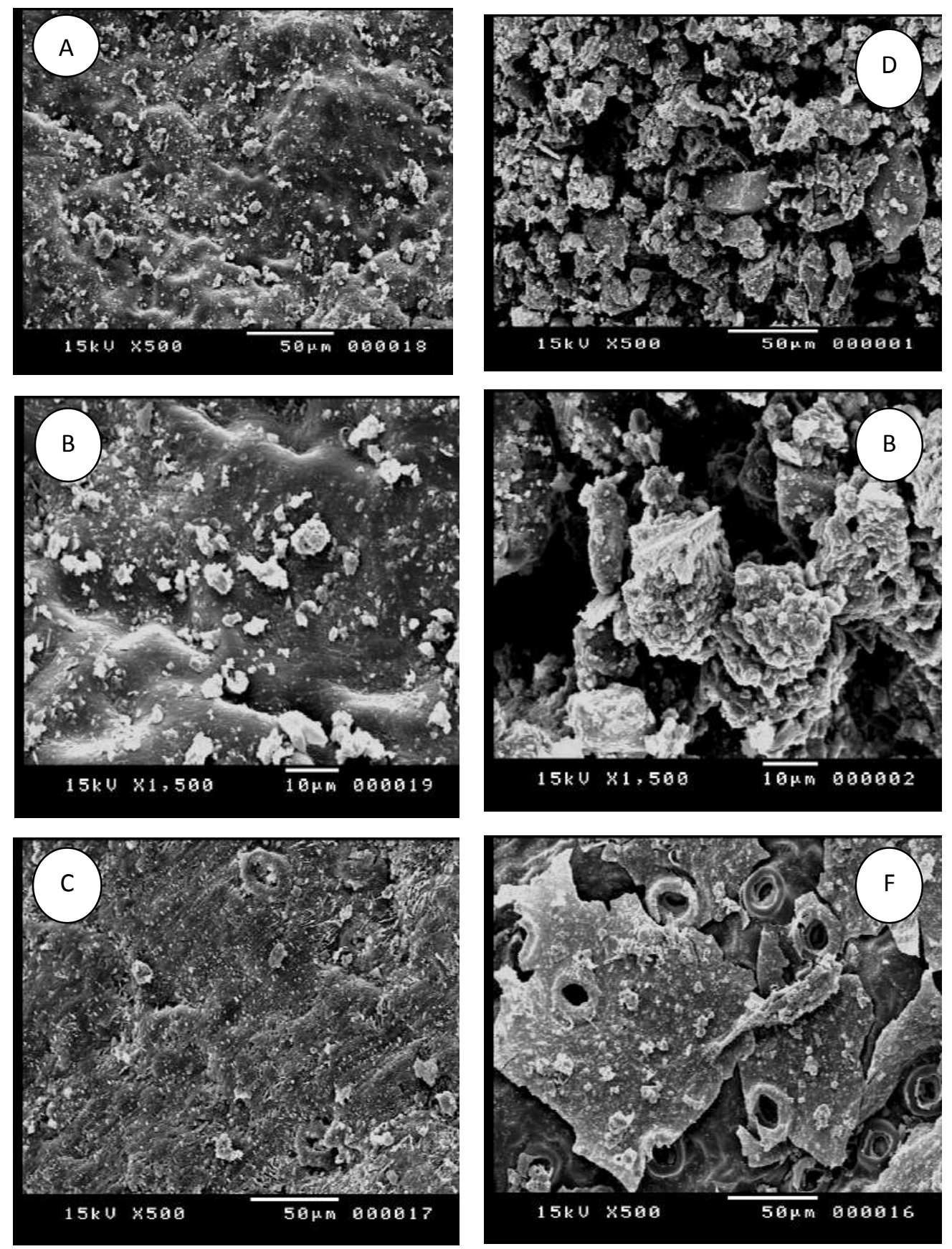

Plate (3): Scanning electron micrographs of the leaf surface of $F$. nitida growing at the control (adaxial $(\mathrm{A}, \mathrm{B})$, abaxial $(\mathrm{C}))$ and polluted sites (adaxial (D, E), abaxial (F)). 


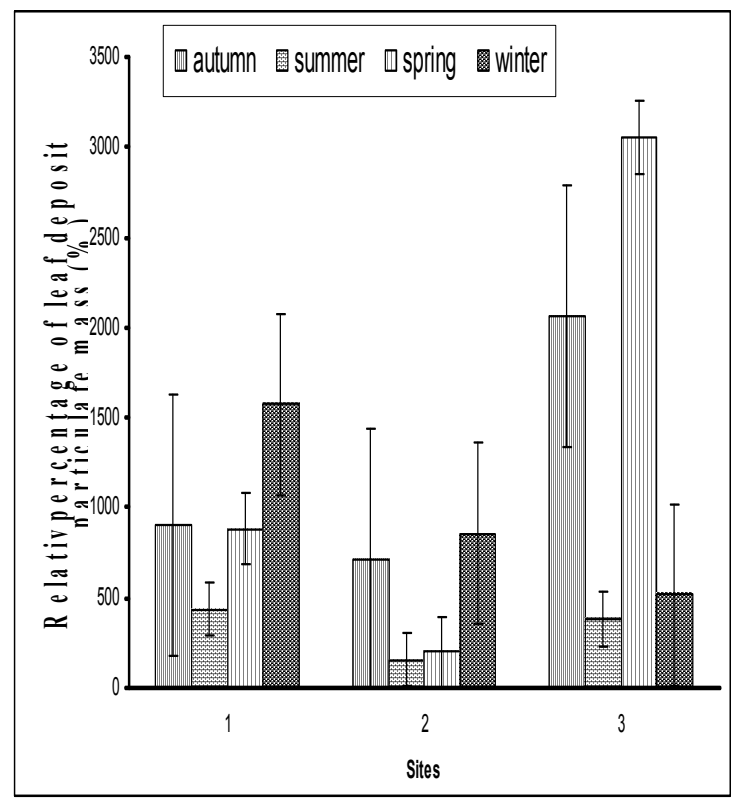

Figure (1): Relative percentage of leaf deposit particulate mass $(M \pm S D)$ captured by the studied plant species F.nitida, E. globules, and $Z$ spina-christi growing at the study sites during the different seasons

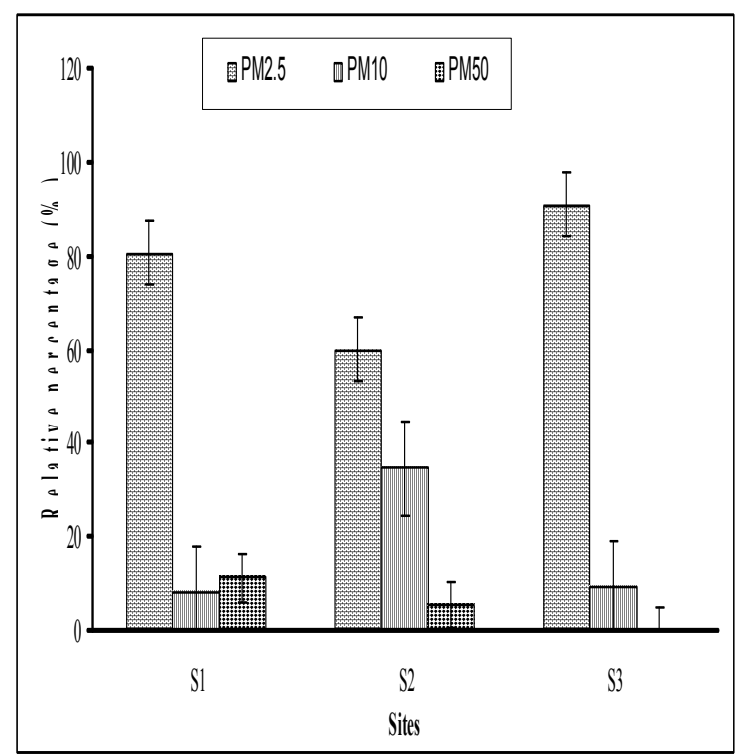

Figure (2): Relative percentage $(\mathrm{M} \pm \mathrm{SD})$ of PM2.5, PM10, PM50 in the leaf deposit per 100 $\mu \mathrm{m} 2$ tree species leaf surface.

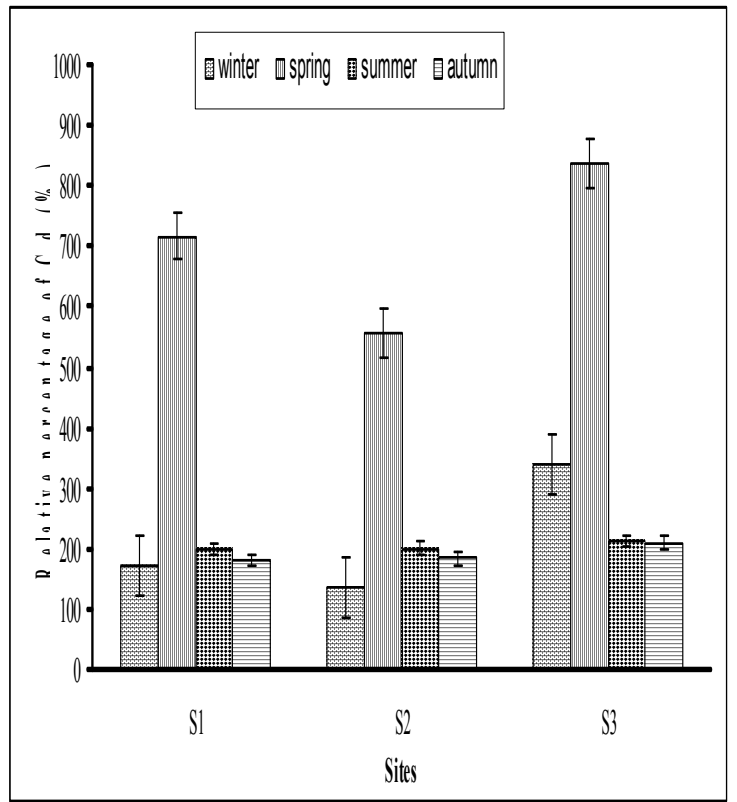

Figure (3): Relative Percentage of deposit $\mathrm{Cd}$ $(\mathrm{M} \pm \mathrm{SD})$ captured by the studied plant species F.nitida, E. globules, and Z spina-christi growing at the study sites during the different seasons.

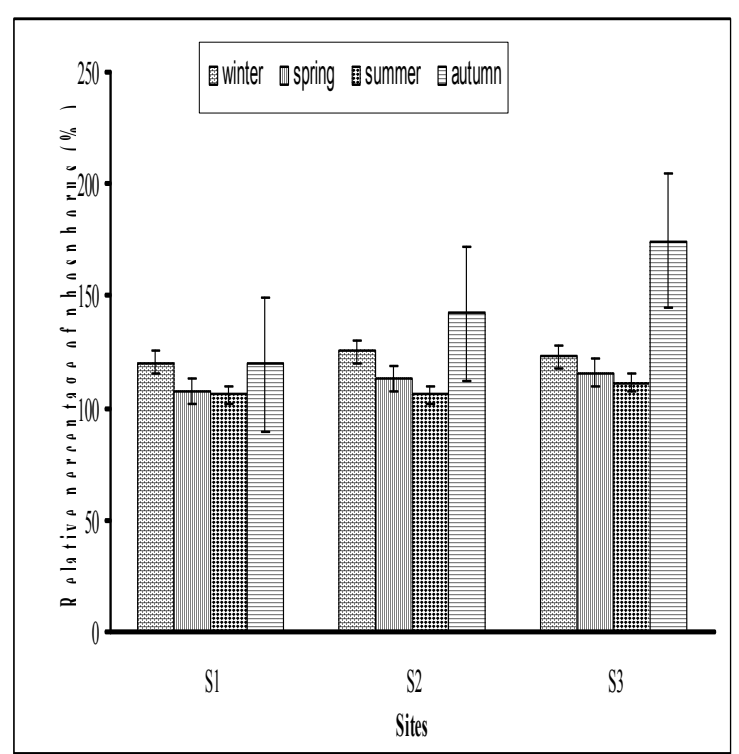

Fig (4): Relative percentage of deposit Fe ( $\mathrm{M} \pm$ SD) captured by the studied plant species F.nitida, E. globules, and Z spina-christi growing at the study sites during the different seasons. 


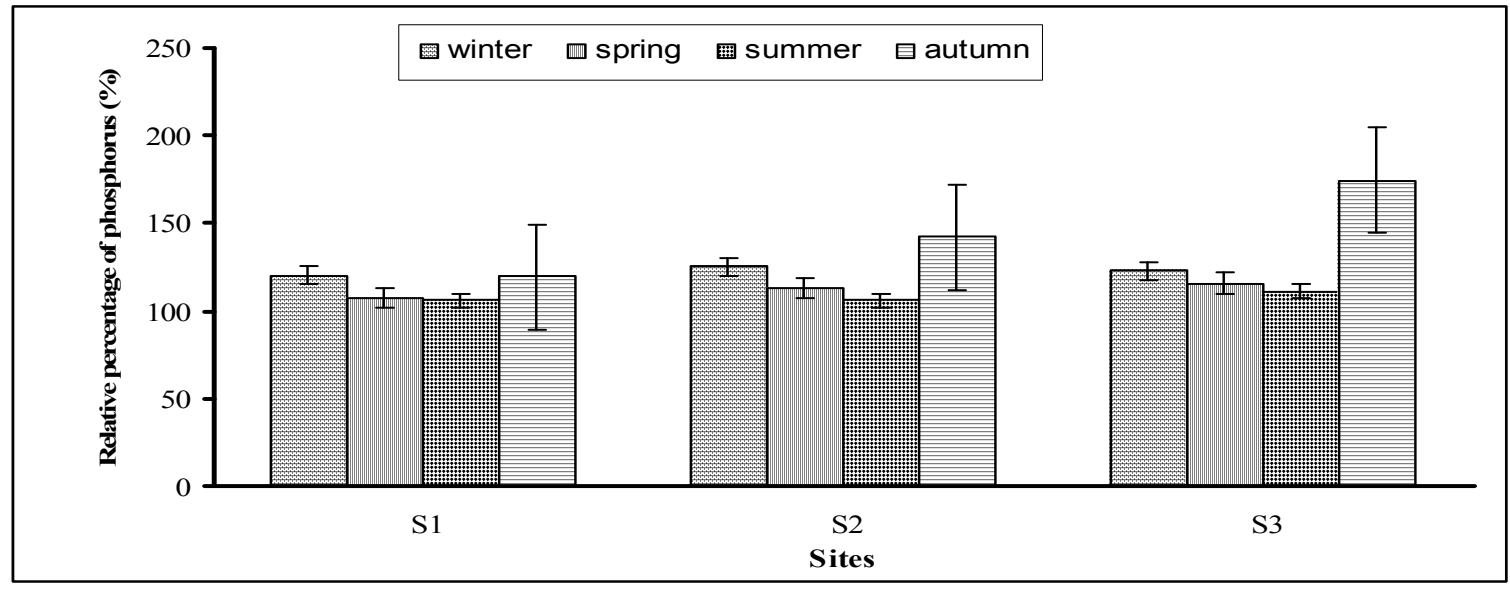

Fig (5): Relative percentage of deposit phosphorus $(\mathrm{M} \pm \mathrm{SD})$ captured by the studied plant species F.nitida, E. globules, and $Z$ spina-christi growing at the study sites during the different seasons.

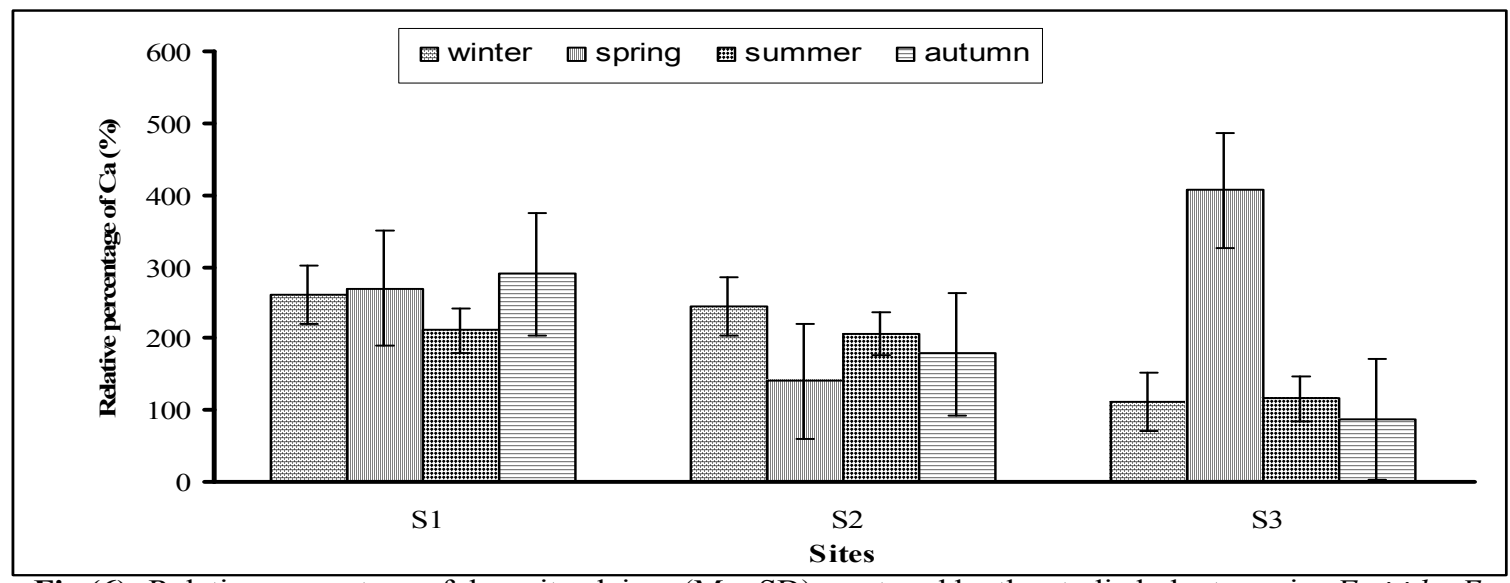

Fig (6): Relative percentage of deposit calcium ( $\mathrm{M} \pm \mathrm{SD}$ ) captured by the studied plant species F.nitida, E. globules, and Z spina-christi growing at the study sites during the different seasons.

\section{References}

Andrew, D., Eaton, Awwa, Chair, Lenore, S., Clesceri, Wef, Arnold, E., Greenberg, A. (1995). Standard method for the examination of water and waste water. American. PUB.H.ASS.19:4,112-121.

Avila, A., Alarcon, M., Rodrigo, A. (2003). Heavy metal deposition andcycling at two Mediterranean holm oak (Quercus ilex L.) forests innortheastern Spain. Journal De Physique IV 107 (1), 75-78.

Beckett, K.P.; Freer-Smith, P. H. and Taylor, G. (1998). Urban Woodlands: Their role in reducing the effect of particulate pollution. Environ. Pollut. 99, 347-360.

Boulus, L. (2000). Flora of Egypt, Volume II, Al Hadara Publising cairo, Egypt.84-86.
Egyptian Environmental Affairs Agency, 2006. Ecological description of Assuit. page1-2

El-Khatib, A.A. and El-Swaf, N. (2001). Phytotoxicity of air particulate pollutants (dust) on the urban trees.Bulletin of faculty of science, assuit university, Egypt.30, 183-193.

El-Khatib, A.A., Faheed, F.A. and Azoz, M.M. (2004). Physiological response of Eucalyptus rostrata to heavy metal air pollution. El-Minia Sci. Bull.14(2), 429441.

El-Khatib, A.A., Manal F., El-Sheikh, O.M.I (2007). Removal of airborne particulate pollutants by leaves of urban trees under dry climate of Upper Egypt, an Emphasis on the metalloid Leaf Deposit. 
International conference for Environment Protection \& Pollution, Qassim, University, KSA.

El-Khatib, A.A., Abdelkalek, K.N., Naglaa Y. (2008). Dust particulate Air Pollutants and the Structural Features of Urban Vegetation. 4th International conference for Development \&Environment 2008, King Saud University, KSA.

Fabiano, T. and Daniel, M.B. (2006). Radionuclides, heavy metals and fluorine incidence at Tapira phosphate rocks, Brazil, and their industrial (by) products. Environmental Pollution ,139: 232-243

Free-Smith, P.H., El-khatib, A.A. Taylor, G. (2004). Capture of particulate pollution by trees: a comparison of species typical of semi-arid areas (Ficus nitida and Eucalyptus globulus) with european and north american species.Water, Air, and Soil pollu. 155,173-187.

Gian, L.C., Fabian, A., Elena, P., Paolo, F., Antonio, G., Anna,S. (2007). Active biomonitoring of heavy metal by rosa ragosa plant. Environmental Pollution 149, 239-245.

Klarschammverordnung, (1982). AbflkaerV, vom 25.6.1982 Bundesgesetzblatt, Teil, I.

Lau, O.W., and Luk, S.F. (2001). Leaves of Bauhinia blakeana as indicator of atmospheric pollution in Hong Kong. Atm. Environ 35:3113-3120.

Lehndorff, E., Schwark, L. (2010). Biomonitoring of air quality in the Cologne Conurbation using pine needles as a passive sampler Part III: Major and trace elements. Atmospheric Environment 44, 2822-2829.

Lohr, V.I. and Pearson-Mims, C.H. (1996). Particulate matter accumulation on horizontal surfaces in interiors: influence of foliage of plants. Atmos. Environ. 30, 2565-2568.

Lugon-Moulin, N.L., Ryan, P., Donini and L. R (2006). Cadmium content of phosphate fertilizers used for tobacco production. Agron. Sustain. Dev. 26 : 151-155.

Nowak, D.J. (1994). Air pollution removal by Chicago's urban forest. In: McPherson, E.G., Nowak, D.J., Rowntree, R.A. (Eds.), Chicago's Urban Forest Ecosystem:
Results of the Chicago Urban Forest Climate Project, USDA Forest Service General Technical Report NE-186, pp. 63-81.

Prusty, B.A.K., Mishra, P.C., Azeez, P. A. (2005). Dust accumulation and leaf pigment content in vegetation near the national high way at sambalpure, Orissa, India. Ecotoxicology and environmental safety. 60: 228-235.

Pyatt, F.B. (2001). Copper and lead bioaccumulation by Acacia retinoides and Eucalyptus torquatain sites contaminated as a consequences of extensive ancient mining activities in Cyprus. Ecotoxicology Environment Safety 50, 60-64.

Sardans, J. and Penuelas, J. (2005). Trace element accumulation in the moss Hypnum cupressiforme Hedw. and trees Quercus ilex L. and Pinus halepensis Mill. in Catalonia. Chemosphere 60, 1293-1307.

Schwarzenbach, G., Biedermann, W. (1948). KomplexoneX, Eradalkalikomplexe Von O,O-Dioxyzofarbstoffen. Helv. Chim. Acta.31:678-687.

Tomasevic, M.Z., Vukmirovic, Z., Rajs`ic, S. M., Tasic, M., Stevanovic, B. (2004). Characterization of trace metal particles deposited on some deciduous tree leaves in an urban area. Chemosphere 61: 753760.

U.S. Environmental Protection Agency (EPA) (1979). Source Assessment: Phosphate Fertilizer Industry, May 1979, EPA600/2-79-019C. Office of Research and Development, Research Triangle Park, NC.

UNEP, (1998). Mineral fertilizer production and the environment. 26 (1), 5-51.

Vallius, M. (2005). Characteristics and source of fine particulate matter. National Public Health Institute Finland.15-20.

Wittig, R. (1993). General aspects of biomonitoring heavy metals by plants. In: Markert, B. (ed.) Plants as biomonitors. Indicators for heavy metals in the terrestrial environment. Verlag Chemie, Weinheim Pp. 3-27. 


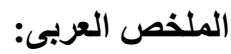

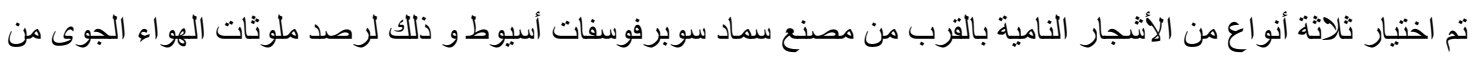

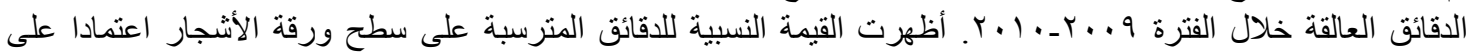

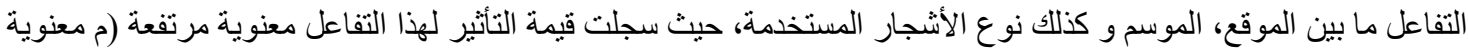

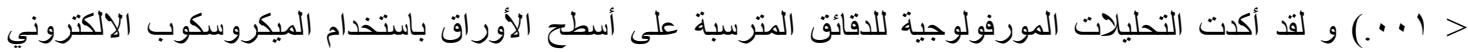

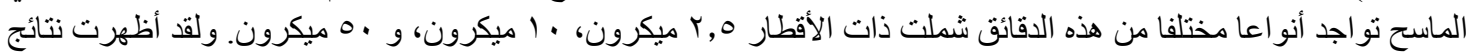

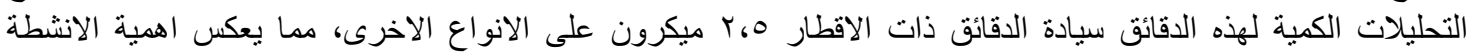

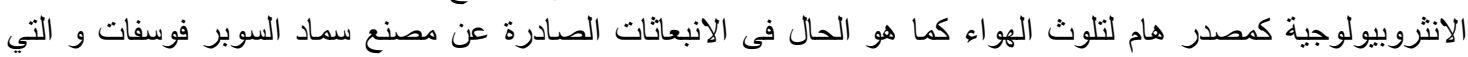

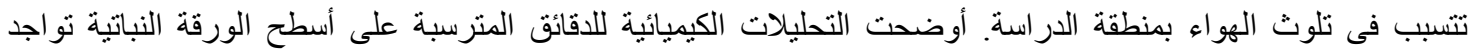

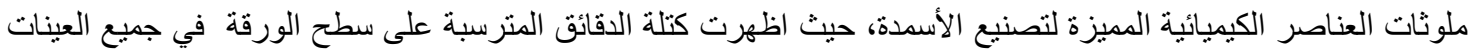

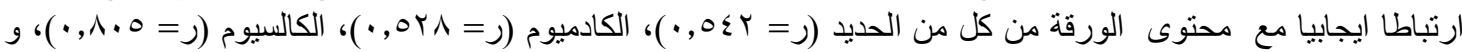

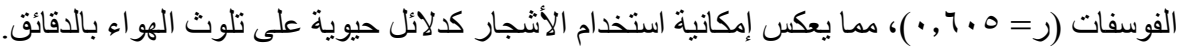

